\title{
Synchronously Improved Voltage Gradient and Mechanical Properties of ZnO Based Varistor by Doping Ga203
}

\section{Bo-wen Wang}

State Key Laboratory of Disaster Prevention and Reduction for Power Grid Transmission and Distribution Equipment

Bao-hui Chen ( $\boldsymbol{Q}$ bymountains@gmail.com)

State Key Laboratory of Disaster Prevention \& Reduction for Power Grid Transmission and Distribution Equipment, State Grid Hunan Electric Power Company Disaster Prevention and Reduction Center, Changsha410129, China;

\section{Peng-zhao Gao}

Hunan University

Hui-hui Chen

Hunan University

\section{Pei Zhang}

Hunan University

\section{Research Article}

Keywords: ZnO-based varistors, doping Ga203, high voltage gradient, abnormal graingrowth, mechanical properties

Posted Date: July 28th, 2020

DOl: https://doi.org/10.21203/rs.3.rs-47615/v1

License: (c) (i) This work is licensed under a Creative Commons Attribution 4.0 International License. Read Full License 


\title{
Synchronously Improved Voltage Gradient and Mechanical Properties of ZnO Based Varistor by Doping $\mathrm{Ga}_{2} \mathrm{O}_{3}$
}

\author{
Bo-wen Wang1, Bao-hui Chen ${ }^{1 *}, \quad$ Peng-zhao $\mathrm{Gao}^{2}, \quad$ Hui-hui Chen², Pei Zhang ${ }^{2}$ \\ 1. State Key Laboratory of Disaster Prevention \& Reduction for Power Grid Transmission and Distribution Equipment, State Grid \\ Hunan Electric Power Company Disaster Prevention and Reduction Center, Changsha 410129, China; \\ 2. College of Materials Science and Engineering, Hunan University, Changsha 410082, China
}

Corresponding author: Bao-hui Chen

Address: State Key Laboratory of Disaster Prevention \& Reduction for Power Grid Transmission and Distribution Equipment, State Grid Hunan Electric Power Company Disaster Prevention and Reduction Center, Changsha410129, China.

Tel: +86 731 86332074; Fax: +86 731 86332011. Email address: bymountains@gmail.com (Bao-hui Chen)

\begin{abstract}
ZnO}$ based varistors with high voltage gradient and excellent mechanical and thermal properties were fabricated by $\mathrm{Ga}_{2} \mathrm{O}_{3}$ doping and using nanoparticles. The compositions and microstructure of the varistors, as well as their electrical, mechanical and thermal properties were investigated by XRD, XPS, SEM, E-J, C-V, mechanical and thermal expansion measurements. Also, the mechanism of $\mathrm{Ga}_{2} \mathrm{O}_{3}$ addition on electrical and mechanical properties of the varistors was discussed detailedly. Results showed that the added $\mathrm{Ga}_{2} \mathrm{O}_{3}$ preferentially occupied the lattice position of $\mathrm{ZnO}$ crystal through the formation of a substitutional solid solution (Donor doping), they then occupied the void position through the formation of an interstitial solid solution (Acceptor doping), in which residual $\mathrm{Ga}_{2} \mathrm{O}_{3}$ existed in the grain boundary and served as inversion boundaries. The formation of the substitutional and interstitial solid solutions helped to improve the electrical properties, when the $\mathrm{Ga}_{2} \mathrm{O}_{3}$ content was $0.40 \mathrm{~mol} \%, E_{1 m A}, \alpha$ and $K$ were $1235.00 \mathrm{~V} \cdot \mathrm{mm}^{-1}, 46.0$ and 1.37 , respectively, being due to the small particle size and the relative content of donor, acceptor and grain boundary in $\mathrm{ZnO}$ grain; The increased content of inversion boundaries stimulated the abnormal growth of $\mathrm{ZnO}$ grain, and the formed plate-like grain helped to improve the mechanical properties and thermal expansion coefficient of the varistors, values of $\sigma_{f}, E_{f}$, and $K_{I C}$ reached 147.43 $\mathrm{MPa}, 213.61 \mathrm{GPa}$ and $2.05 \mathrm{MPa} \cdot \mathrm{m}^{1 / 2}$, showing improvements of $25.29 \%, 47.67 \%$, and $38.51 \%$, respectively, compared with those of $\mathrm{ZnO}$ varistors without $\mathrm{Ga}_{2} \mathrm{O}_{3}$.
\end{abstract}

Key words: $\mathrm{ZnO}$-based varistors; doping $\mathrm{Ga}_{2} \mathrm{O}_{3}$; high voltage gradient; abnormal grain growth; mechanical properties 


\section{Introduction}

$\mathrm{ZnO}$ varistors are a typical polycrystalline ceramic obtained by sintering $\mathrm{ZnO}$ powder with minor primary additives, such as $\mathrm{Bi}_{2} \mathrm{O}_{3}, \mathrm{Pr}_{6} \mathrm{O}_{11}$ and $\mathrm{V}_{2} \mathrm{O}_{5}{ }^{[1-3]}$, and secondary additives such as $\mathrm{Sb}_{2} \mathrm{O}_{3}, \mathrm{SiO}_{2}, \mathrm{Co}_{2} \mathrm{O}_{3}, \mathrm{MnO}_{2}, \mathrm{Al}_{2} \mathrm{O}_{3}$, $\mathrm{Cr}_{2} \mathrm{O}_{3}, \mathrm{Ni}_{2} \mathrm{O}_{3}, \mathrm{Ga}_{2} \mathrm{O}_{3}$, and $\mathrm{In}_{2} \mathrm{O}_{3}{ }^{[4,5]}$, it mainly works as a surge-protection device and is extensively applied in electronic and electrical systems to limit overvoltage ${ }^{[6,7,]}$. Therefore, voltage gradient of $\mathrm{ZnO}$ varistors is an important parameter for evaluating the performance of $\mathrm{ZnO}$ varistors, which can be improved through sintering modification ${ }^{[1,8,9]}$, particle-size choice ${ }^{[6]}$, and composition design ${ }^{[3-5,10,11]}$. For these three protocols, improving the electrical properties via composition design possesses the advantages of easy operation, wide adjustment of electrical properties, and excellent comprehensive properties of the obtained varistors, among others. Accordingly, many researchers focus on this field ${ }^{[12-14]}$.

Multiple donor such as $\mathrm{Al}^{3+}, \mathrm{Ga}^{3+}, \mathrm{In}^{3+}$, or $\mathrm{Y}^{3+}$ trivalent ion metallic oxide have been alternatively employed to enhance the comprehensive performance of $\mathrm{ZnO}$ varistor for their special electronic donor structure as well as similar ion radius between these ions and $\mathrm{Zn}^{2+[4,5,15]}$, while the multiple dopants may result in a lower voltage gradient, $517 \mathrm{~V} \cdot \mathrm{mm}^{-1[4]}, 479 \mathrm{~V} \cdot \mathrm{mm}^{-1}[15]$ and $475 \mathrm{~V} \cdot \mathrm{mm}^{-1[16]}$, although other electrical properties of the obtained $\mathrm{ZnO}$ varistor are excellent, such as lower residual voltage(1.60) and leakage current $\left(0.96 \mu \mathrm{A} \cdot \mathrm{cm}^{-2}\right)$ as well as the higher nonlinear coefficient(87) ${ }^{[4]}$, it still hinders the application of these $\mathrm{ZnO}$ varistor in high voltage field. Several researchers focus on the effect of single $\mathrm{Ga}_{2} \mathrm{O}_{3}$ addition on the varistor characteristics of $\mathrm{ZnO}$ varistor ${ }^{[17,18]}$, and the associated mechanism has been reported ${ }^{[4]}$, while the disadvantage of lower voltage gradient has not been solved. Liu ${ }^{[6]}$ and Vukovic ${ }^{[19]}$ report that the voltage gradient of $\mathrm{ZnO}$ varistors can be improved by using nanoparticles as main raw materials. In addition, according to Danzer's opinion, the reason for mechanical and electrical failure of $\mathrm{ZnO}$ varistors is correlated. Therefore, a high strength of varistor material are both beneficial for its electrical strength and reliability ${ }^{[20,21]}$; on the other hand, Raidl thinks that the electrical barriers at the grain boundaries of $\mathrm{ZnO}$ varistors are altered by mechanical stresses, which is derived from the externally applied stress as well as micro stresses that evolve naturally during fabrication of materials with anisotropic thermal expansion coefficients $^{[22]}$, namely, the coefficient of thermal expansion (CTE) could also affect the electrical strength and reliability of $\mathrm{ZnO}$ varistors.

In summary, the electrical properties of the trivalent ion metallic oxide doped $\mathrm{ZnO}$ varistors have been extensively studied ${ }^{[23,24]}$, but it still exists some deficiencies(such as lower voltage gradient), also the effect of dopants on the mechanical and thermal properties of $\mathrm{ZnO}$ varistors is rarely reported. In this work, we introduced various $\mathrm{Ga}$ additives into a $\mathrm{ZnO}$ based varistor and selected nano- $\mathrm{ZnO}$ particles as the main raw materials to try to 
improve the voltage gradient and mechanical properties, modify the thermal properties of $\mathrm{ZnO}$ based varistors at same time. Furthermore, the mechanism of improving the electrical, thermal and mechanical properties of $\mathrm{ZnO}$ based varistors was studied system and some interesting results were obtained.

\section{Experimental procedure}

\subsection{Raw materials}

All oxides used were $99.9 \%$ pure and commercially obtained from Aladdin company. Nano-ZnO powders with particle sizes of $30 \pm 10 \mathrm{~nm}$ were used as the main materials. Other oxides such as $\mathrm{Bi}_{2} \mathrm{O}_{3}, \mathrm{Sb}_{2} \mathrm{O}_{3}, \mathrm{Co}_{2} \mathrm{O}_{3}, \mathrm{SiO}_{2}$, $\mathrm{MnO}_{2}, \mathrm{Cr}_{2} \mathrm{O}_{3}$, and $\mathrm{Ga}_{2} \mathrm{O}_{3}$ with particle sizes of $1.0 \pm 0.5 \mu \mathrm{m}$ served as additives.

\subsection{Preparation of the $\mathrm{Ga}_{2} \mathrm{O}_{3}$ doped $\mathrm{ZnO}$ based varistors}

The composition design of the $\mathrm{Ga}_{2} \mathrm{O}_{3}$ doped $\mathrm{ZnO}$ based varistors followed Ref. [4] with a minor adjustments: (95.0-x) mol\% $\mathrm{ZnO}, 1.0 \mathrm{~mol} \% \mathrm{Bi}_{2} \mathrm{O}_{3}, 1.0 \mathrm{~mol} \% \mathrm{Sb}_{2} \mathrm{O}_{3}, 1.0 \mathrm{~mol} \% \mathrm{Co}_{2} \mathrm{O}_{3}, 1.0 \mathrm{~mol} \% \mathrm{SiO}_{2}, 0.5 \mathrm{~mol} \% \mathrm{MnO}_{2}, 0.5$ $\operatorname{mol} \% \mathrm{Cr}_{2} \mathrm{O}_{3}$, and $x \mathrm{~mol} \% \mathrm{Ga}_{2} \mathrm{O}_{3}(x=0,0.20,0.40,0.60,0.80)$.

Oxides at appropriate ratios were mixed until homogenization by using a planetary mill, where alcohol was used as the medium and $\mathrm{ZrO}_{2}$ ball was the abrasive. The homogenized mixture was dried at $80{ }^{\circ} \mathrm{C}$ to remove alcohol, and then a small amount of PVA binder solution was added into the dried mixture. After subjecting to an aging process, the mixture was pressed at $100 \mathrm{MPa}$ into disks with $30 \mathrm{~mm}$ diameter and $3.0 \mathrm{~mm}$ thickness. These disks were sintered at different temperatures and holding time at a heating rate of $4{ }^{\circ} \mathrm{C} \cdot \mathrm{min}^{-1}$ and a cooling rate of $2{ }^{\circ} \mathrm{C} \cdot \mathrm{min}^{-1}$ in air. After sintering, the upper and lower surfaces of $\mathrm{ZnO}$ varistor samples were polished and then covered with silver paste, and then these samples were heated at $600{ }^{\circ} \mathrm{C}$ for $10 \mathrm{~min}$ in air to form electrodes ${ }^{[1]}$.

The corresponding $\mathrm{ZnO}$ based varistors were labeled as GaX-T-t, where index GaX represented the amount of $\mathrm{Ga}_{2} \mathrm{O}_{3}, T$ was the sintered temperature in degrees Celsius, and $t$ was the holding time at the sintered temperature.

\subsection{Characterization of the $\mathrm{Ga}_{2} \mathrm{O}_{3}$ doped $\mathrm{ZnO}$ based varistors}

Bulk density of $\mathrm{ZnO}$ based varistors were measured using Archimedes method ${ }^{[25]}$.

The phase constitution of $\mathrm{ZnO}$ based varistor was analyzed via an in-situ X-ray diffraction analysis (XRD, Smartlab, Rigaku, Japan) when $C u K_{\alpha}$ worked as radiation and surface of the varistor was pre-polished. $2 \theta$ ranged between $10^{\circ}$ and $70^{\circ}$ and the scan speed was $1^{\circ} \cdot \mathrm{min}^{-1}$.

Microstructure of $\mathrm{ZnO}$ based varistor was examined via scanning electron microscopy (SEM, Regulus 8100, Hitachi, Japan) when the surface of specimen was pre-polished and glass phase was removed via etching method ${ }^{[1]}$. 
The electric field-current density $(E-J)$ characteristic of $\mathrm{ZnO}$ based varistor was obtained via a source measurement unit (Keithley 2410, USA). The voltage gradient $\left(E_{1 m A}\right)$ is the breakdown voltage at a unit height, and the leakage current $\left(J_{L}\right)$ is determined at $0.75 U_{1 m A}$, the nonlinear coefficient $(\alpha)$ is defined by $\operatorname{Eq}(1)^{[1]}$ :

$$
\alpha=\frac{\log \left(J_{2} / J_{1}\right)}{\log \left(E_{2} / E_{1}\right)}
$$

Where $E_{2}$ is the corresponding electric field at $J_{2}=1 \mathrm{~mA} \cdot \mathrm{cm}^{-2}$ and $E_{1}$ is the corresponding electric field at $J_{1}=$ $0.1 \mathrm{~mA} \cdot \mathrm{cm}^{-2}$. The residual voltage ratio $K$ is calculated according to $\mathrm{Eq}(2)$ :

$$
K=U_{n} / U_{1 m A}
$$

Where $U_{n}$ is the voltage under a current density of $63.7 \mathrm{~A} \cdot \mathrm{cm}^{-2}$, which is the standard requirement for the surge arresters applied in ultrahigh voltage $(1000 \mathrm{kV} \mathrm{AC})$ system ${ }^{[23]}$

The capacitance-voltage $(C-V)$ measurement of $\mathrm{ZnO}$ based varistor was determined under DC bias voltages using a broadband dielectric device (Novocontrol Concept 80, Germany). The most important parameters related to the Schottky barrier, including barrier height $\left(\varphi_{b}\right)$, donor density $\left(N_{d}\right)$ and interface state density $\left(N_{s}\right)$, these values can be calculated according to $\operatorname{Eq}(3)^{[4]}$ :

$$
\left(\frac{1}{c}-\frac{1}{2 C_{o}}\right)^{2}=\frac{2\left(\phi_{b}+V_{g b}\right)}{q \cdot \varepsilon_{s} \cdot N_{d}}
$$

In which $C$ is the capacitance at a unit area for a single grain boundary when biased voltage for a single grain boundary is $V_{g b}, \mathrm{C}_{0}$ is the capacitance when $V_{g b}=0, q$ is the electronic charge, and $\varepsilon_{s}$ is the permittivity of $\mathrm{ZnO}$ grain. $\varphi_{b}$ and $N_{d}$ are calculated via the intercept and the slope of the curve of $\left(\frac{1}{C}-\frac{1}{2 C_{o}}\right)^{2}$ versus $V_{g b}$, respectively. Besides, after getting $\varphi_{\mathrm{b}}$ and $N_{d}, N_{s}$ is obtained by equations (4) ${ }^{[4]}$ :

$$
N_{\mathrm{s}}=\sqrt{\frac{2 \cdot \varepsilon_{\mathrm{s}} \cdot N_{d} \cdot \phi_{b}}{q}}
$$

An Instron 3382 universal electronic experimental machine was conducted the mechanical properties measurement of $\mathrm{ZnO}$ based varistor. All specimens were grind and the tensile surfaces were polished better than 1 $\mu \mathrm{m}$ in advance, the edge of specimen was beveled to avoid stress concentration during testing. The size of the specimen were $3 \mathrm{~mm}$ (height) $\times 2 \mathrm{~mm}$ (width) $\times 30 \mathrm{~mm}$ (length), a batch of five specimens was tested and the obtained values were averaged. Three - point flexural strength $\left(\sigma_{f}\right)$ of the varistor was measured in a span of $20 \mathrm{~mm}$ and a loading rate of $0.5 \mathrm{~mm} \mathrm{~min}^{-1}$, the slope of stress-strain curve can be used to calculate the modulus of elasticity $\left(E_{f}\right)$. The fracture toughness $\left(K_{I C}\right)$ of the specimen was measured via the single-edge-notched- beam method 
(SENB), with a span of $20 \mathrm{~mm}$ and a loading velocity of $0.5 \mathrm{~mm} \mathrm{~min}^{-1}$, notches were incised in the middle of the specimen along the height with a width of $0.3 \mathrm{~mm}$ to the depth of about $0.2 \mathrm{~mm}^{[26]}$.

The coefficient of thermal expansion (CTE) of $\mathrm{ZnO}$ based varistor was measured via a high-temperature dilatometer (Model DIL 402E, Netzsch, Selb, Germany) under an air atmosphere with a heating rate of $10^{\circ} \mathrm{C} \min ^{-1}$.

\section{Results and discussion}

\subsection{Influences of sintering process on the composition and microstructure of $\mathrm{ZnO}$ based varistors}

\subsubsection{Volume density and linear shrinkage of $\mathrm{ZnO}$ based varistors}

Bulk density plays an important role in the electrical properties of $\mathrm{ZnO}$ varistors ${ }^{[25]}$. Figure 1 (a) shows the measured bulk density $(\rho)$ of $\mathrm{ZnO}$ varistors sintered at different temperatures for $2 \mathrm{~h}$. Clearly, with increased sintered temperatures, value of $\rho$ initially increased and then decreased. All reached the maximum at $1100{ }^{\circ} \mathrm{C}$ due to particle growth and densification behavior ${ }^{[8]}$; Moreover, with increased $\mathrm{Ga}_{2} \mathrm{O}_{3}$ addition, $\rho$ initially increased and then decreased, and when the addition of $\mathrm{Ga}_{2} \mathrm{O}_{3}$ was $0.4 \mathrm{~mol} \%$ and the sintering temperature was $1100{ }^{\circ} \mathrm{C}, \rho$ reached the maximum $\left(5.59 \mathrm{~g} \cdot \mathrm{cm}^{-3}\right)$. According to Wang opinion, when the addition of $\mathrm{Ga}_{2} \mathrm{O}_{3}$ was lower, $\mathrm{Ga}^{3+}$ preferentially occupied the lattice position of $\mathrm{ZnO}$ crystal via the formation of a substitutional solid solution, further increased $\mathrm{Ga}_{2} \mathrm{O}_{3}$ addition resulted in a partially occupied void position and partially occupied lattice position of $\mathrm{ZnO}$ crystal because of the smaller ion radii $\left(0.062 \mathrm{~nm} \text { for } \mathrm{Ga}^{3+} \text { and } 0.075 \mathrm{~nm} \text { for } \mathrm{Zn}^{2+}\right)^{[27]}$. The formation of a $\mathrm{Gd}^{3+}$ solid solution in $\mathrm{ZnO}$ crystal could reduce the lattice energy ${ }^{[28]}$, and the small particle size of raw $\mathrm{ZnO}(30 \mathrm{~nm})$ could reduce the sintering activation energy ${ }^{[6]}$, both factors helped improve the densification of $\mathrm{ZnO}$ varistors ${ }^{[6]}$. When the addition of $\mathrm{Ga}_{2} \mathrm{O}_{3}$ exceeded $0.04 \mathrm{~mol} \%$, some additives may existed in the grain boundary of $\mathrm{ZnO}$ crystal to inhibit $\mathrm{ZnO}$ grain growth and reduce the density of the $\mathrm{ZnO}$ varistors ${ }^{[4]}$.

Figure 1 (b) shows the $\rho$ value of the $\mathrm{ZnO}$ varistors for different holding times at $1100{ }^{\circ} \mathrm{C}$. Similar trends can be observed, as shown in Fig. 1. When the holding time was $2 \mathrm{~h}$, all values reached maximum. Thus, more detailed research should focus on $\mathrm{ZnO}$ varistors sintered at $1100{ }^{\circ} \mathrm{C}$ for $2 \mathrm{~h}$.

\section{Please insert Figure 1 here}

\section{Please insert Figure 2 here}




\subsubsection{Phase identification of $\mathrm{ZnO}$ based varistors}

The surface of $\mathrm{ZnO}$ based varistors was polished to analyze their composition with a slow scan speed of $1^{\circ} \cdot \mathrm{min}^{-1}$, and results are shown in Figure 2. As shown in Fig.2-a, the main composition of 6H-ZnO phase (JCPDS no.79-2205), a small amount of spinel phase $\mathrm{Zn}_{7} \mathrm{Sb}_{2} \mathrm{O}_{12}$ (JCPDS no.36-1445), $\mathrm{Zn}_{2} \mathrm{SiO}_{4}$ phase (JCPDS no.70-1235), $\beta-\mathrm{Bi}_{2} \mathrm{O}_{3}$ (JCPDS no.78-1793), and $\gamma-\mathrm{Bi}_{2} \mathrm{O}_{3}$ (JCPDS no.76-2478) were detected in $\mathrm{ZnO}$ varistors regardless of $\mathrm{Ga}_{2} \mathrm{O}_{3}$ amount, similar to the findings of $\mathrm{Fu}^{[1]}$ and $\mathrm{Zhao}{ }^{[4]}$. The $\mathrm{Ga}_{2} \mathrm{O}_{3}$ phase was not observed in the specimens, which can be attributed to the small amount ${ }^{[4]}$.

An interesting appearance can be observed in Fig.2-b that with increased $\mathrm{Ga}_{2} \mathrm{O}_{3}$ addition, diffraction peak of $\mathrm{ZnO}$ firstly moved toward a higher degree and then moved back, as we know that the ion radius of $\mathrm{Ga}^{3+}$ is slightly smaller than that of $\mathrm{Zn}^{2+}$, so when the amount of $\mathrm{Ga}^{3+}$ added was small (e.g., $\mathrm{x}=0.2, \mathrm{Ga} 0.2-1100-2 \mathrm{~h}$ ), it prioritized occupying the lattice position of $\mathrm{ZnO}$ in the form of a substitutional solid solution, causing the lattice constant of $\mathrm{ZnO}$ crystal to decrease and the diffraction peak to move toward a higher degree; When the addition of $\mathrm{Ga}_{2} \mathrm{O}_{3}$ was further increased, most $\mathrm{Ga}^{3+}$ ions still occupied the lattice position, whereas some $\mathrm{Ga}^{3+}$ ions begun to occupy the pores of $\mathrm{ZnO}$ crystal, which could cause the lattice constant to increase and the diffraction peak to move toward a lower degree, similar to the findings of Qiu ${ }^{[29]}$, and the residual $\mathrm{Ga}_{2} \mathrm{O}_{3}$ could exist in the grain boundary but did not affect the lattice constant of $\mathrm{ZnO}$ crystal(e.g., $\mathrm{x} \geq 0.4$ ). Thus, the shift of the $\mathrm{ZnO}$ diffraction peak resulted from the interaction of these two effects, as shown in Figure 2 (b).

\section{Please insert Figure 2 here}

To increase understanding of the composition and chemical states, XPS spectra of $\mathrm{Zn}_{2 \mathrm{p}}, \mathrm{Bi}_{4 \mathrm{f}}$, and $\mathrm{Ga}_{2 \mathrm{p}}$ of $\mathrm{ZnO}$ varistors with different $\mathrm{Ga}_{2} \mathrm{O}_{3}$ contents were obtained and were displayed in Figure 3. The collected spectra were analyzed with XPSPEAK software, and a Shirley type background subtraction was used to fit the curve ${ }^{[30]}$. The binding energy (B.E.) and relative ratio (R.R. calculated from the relative area) under deconvoluted XPS peaks are listed in Table 1.

In the survey spectrum (Fig. 3(a)), peaks associated with $\mathrm{Zn}_{2 \mathrm{p}}, \mathrm{Bi}_{4 \mathrm{f}}$, and $\mathrm{Ga}_{2 \mathrm{p}}$ were detected. In the high-resolution spectra obtained for the $\mathrm{Zn}_{2 \mathrm{p}}$ region (Fig. 3 (b)), two peaks corresponding to $\mathrm{Zn} 2 \mathrm{p}_{1 / 2}$ and $\mathrm{Zn} 2 \mathrm{p}_{3 / 2}$ at B.E. values of $\sim 1021.40$ and $\sim 1044.50 \mathrm{eV}$ were located and attributed to the existence of $\mathrm{ZnO}$ [31]. Fig. 3(c) depicted the high-resolution spectra obtained for $\mathrm{Bi}_{4 \mathrm{f}}$ region. The B.E.s at $\sim 164.41$ and $\sim 158.90 \mathrm{eV}$ were ascribed to Bi $4 \mathrm{f}_{5 / 2}$ and $\mathrm{Bi} 4 \mathrm{f}_{7 / 2}$, respectively. The separation between $\mathrm{Bi} 4 \mathrm{f}_{7 / 2}$ and $\mathrm{Bi} 4 \mathrm{f}_{5 / 2}$ was about $5.5 \mathrm{eV}$, which was 
characteristic of $\mathrm{Bi}^{3+}$ in $\beta-\mathrm{Bi}_{2} \mathrm{O}_{3}$ according to a previous report ${ }^{[32]}$. Moreover, the B.E.s at $\sim 165.02$ and $\sim 159.50 \mathrm{eV}$ were ascribed to $\mathrm{Bi} 4 \mathrm{f} 5 / 2$ and $\mathrm{Bi} 4 \mathrm{f}_{7 / 2}$ of $\mathrm{Bi}^{3+}$ in $\gamma-\mathrm{Bi}_{2} \mathrm{O}_{3}$, respectively ${ }^{[33]}$. Interestingly, with increased $\mathrm{Ga}_{2} \mathrm{O}_{3}$ content, the ratio of $\gamma-\mathrm{Bi}_{2} \mathrm{O}_{3}$ to $\beta-\mathrm{Bi}_{2} \mathrm{O}_{3}$ slightly moved to $1: 1$, as listed in Table 1 .

As shown in Fig. 3(d), the B.E. peaks of $\mathrm{Ga}_{2 \mathrm{p}}$ spectra were at 1116.22, 1116.60, and $1117.02 \mathrm{eV}$, corresponding to the substitutional solid solution, interstitial solid solution, and boundary phase of $\mathrm{Ga}_{2} \mathrm{O}_{3}$ in $\mathrm{ZnO}$ crystal, respectively ${ }^{[27,34,35]}$. It can be seen that with the increase of $\mathrm{Ga}_{2} \mathrm{O}_{3}$ content, the abundance ratio of $a / b / c$ calculated from the area under the peaks exhibited that $\mathrm{Ga}^{3+}$ preferentially formed a substitutional solid solution in $\mathrm{ZnO}$ crystal (as $a / b / c=0.63: 0.18: 0.19$ in Ga0.20-1100-2h); with increased $\mathrm{Ga}^{3+}$ content, the amounts of $\mathrm{Ga}^{3+}$ for the formation of substitutional solid solution was still higher than that for the formation of interstitial solid solution, while the amount of $\mathrm{Ga}_{2} \mathrm{O}_{3}$ in the grain boundary increased quickly, and acted as the main phase when content of $\mathrm{Ga}_{2} \mathrm{O}_{3}$ equaled to 0.8 (as $a / b / c=0.32: 0.20: 0.48$ in $\mathrm{Ga} 0.80-1100-2 \mathrm{~h}$ ), similar to Wang's result ${ }^{[27]}$. High content of $\mathrm{Ga}_{2} \mathrm{O}_{3}$ in the grain boundary might affect the grain growth behavior of $\mathrm{ZnO}$ varistors.

\section{Please insert Figure 3 here}

\section{Please insert Table 1 here}

Figure 4 shows the absolute amount of $\mathrm{Ga}^{3+}$ for different distribution positions with the increased $\mathrm{Ga}_{2} \mathrm{O}_{3}$ content. It can be seen that with the increase of $\mathrm{Ga}_{2} \mathrm{O}_{3}$ content, the amount of $\mathrm{Ga}^{3+}$ in three forms monotonically increased, and that of substitutional solid solution was always higher than the interstitial solid solution, the amount of grain boundary phase increased steeply, it exceeded the amount of substitutional solid solution when content of $\mathrm{Ga}_{2} \mathrm{O}_{3}$ exceeded $0.60 \mathrm{~mol} \%$; the difference between the amount of substitutional solid solution and interstitial solid solution reached maximum when content of $\mathrm{Ga}_{2} \mathrm{O}_{3}$ equaled to $0.40 \mathrm{~mol} \%$.

\section{Please insert Figure 4 here}

\subsubsection{Microstructure characteristics of $\mathrm{ZnO}$ based varistors}

The SEM images of $\mathrm{ZnO}$ based varistors with various $\mathrm{Ga}_{2} \mathrm{O}_{3}$ contents are presented in Figures 5 (a)- (e). The average grain size $(d)$ and maximum and minimum aspect ratios of these specimens determined by the lineal intercept method are exhibited in Figure 5 (f). Interestingly, with increased $\mathrm{Ga}_{2} \mathrm{O}_{3}$ content, the particle shape of 
$\mathrm{ZnO}$ varistors transformed from ellipse into plate-like, similar to Daneu's report [36], for examples, particle shapes of Ga0.00-1100-2h exhibited typical ellipse, while that of Ga0.20-1100-2h displayed obviously plate-like, a further increased $\mathrm{Ga}_{2} \mathrm{O}_{3}$ content resulted in an increased aspect ratios of plate-like particles for $\mathrm{ZnO}$ varistors , as shown in Figure 5 (f). According to Zhao's report, no plate-like grain was observed even after adding $1.44 \mathrm{~mol} \% \mathrm{Ga}_{2} \mathrm{O}_{3}$ and calcination at $1200{ }^{\circ} \mathrm{C}$ for $2 \mathrm{~h}$ in $\mathrm{ZnO}-\mathrm{Bi}_{2} \mathrm{O}_{3}$ based varistors, owing to the high sintering activity of $\mathrm{ZnO}$ nanoparticles $(\sim 30 \mathrm{~nm})^{[37]}$. In addition, the average grain size slightly decreased with increased $\mathrm{Ga}_{2} \mathrm{O}_{3}$ content, suggesting that the dopant concentration minimally influenced the $\mathrm{ZnO}$ grain size ${ }^{[37]}$.

As shown in Figure 5(f), it can be seen clearly that with increased $\mathrm{Ga}_{2} \mathrm{O}_{3}$ content, the maximum and minimum aspect ratios initially increased slowly and then rapidly due to the content of inversion boundaries (IBs; where $\mathrm{Ga}_{2} \mathrm{O}_{3}$ existed in the grain boundary in $\mathrm{ZnO}$ grain) initially increasing slowly and then rapidly ${ }^{[36]}$, being consist with XPS result (as shown in Figure 4). According to Nina's opinion ${ }^{[36]}$, IBs are a major factor influencing $\mathrm{ZnO}$ grain growth. Under the influence of IB-forming dopants (such as $\mathrm{SnO}_{2}, \mathrm{TiO}_{2}$, and $\mathrm{Sb}_{2} \mathrm{O}_{3}$ ), IB nucleation occurred in $\mathrm{ZnO}$ grains, and these grains grew dramatically and anisotropically in the direction of the inherent IB, causing plate-like development of the grains. Given the smaller ionic radius of $\mathrm{Ga}^{3+}$ than that of $\mathrm{Sb}^{3+}(0.076 \mathrm{~nm})^{[24,38]}$ and its larger electronegativity (1.579) than that of $\mathrm{Sb}^{3+}(1.476){ }^{[39]}$, when $\mathrm{Ga}_{2} \mathrm{O}_{3}$ existed in the grain boundary, $\mathrm{Ga}^{3+}$ could work as an IB-forming dopant and affect the growth behavior of $\mathrm{ZnO}$ grain more efficiently. When combined with the XPS results in Figure 4, we can see that with increased $\mathrm{Ga}_{2} \mathrm{O}_{3}$ in $\mathrm{ZnO}$ varistors, $\operatorname{more} \mathrm{Ga}_{2} \mathrm{O}_{3}$ existed in the grain boundary, consequently, the maximum and minimum aspect ratios of $\mathrm{ZnO}$ grain initially increased slowly and then rapidly.

\section{Please insert Figure 5 here}

\subsection{Influence of $\mathrm{Ga}_{2} \mathrm{O}_{3}$ content on the electrical properties of $\mathrm{ZnO}$ based varistors}

Figure 6 shows the electrical field-current density $(E-J)$ and capacitance-voltage $(C-V)$ plots of $\mathrm{ZnO}$ based varistors with various $\mathrm{Ga}_{2} \mathrm{O}_{3}$ amounts and sintered at $1100{ }^{\circ} \mathrm{C}$ for $2 \mathrm{~h}$. The electrical parameters of the specimen deduced from these are summarized in Table 2 , where $E_{1 m A}, J_{L}, \alpha$, and $K$ represent the voltage gradient, leakage current, nonlinear coefficient, and residual voltage ratio, respectively. From Table 2, it can be seen clearly that with increased $\mathrm{Ga}_{2} \mathrm{O}_{3}$, values of $E_{I m A}, J_{L}$, and $\alpha$ initially increased and then decreased. Conversely, $K$ exhibited the opposite trend, $E_{I m A}$ and $\alpha$ had the maximum values of $1235 \mathrm{~V} \cdot \mathrm{mm}^{-1}$, and 46.0 , while $K$ possessed the lowest value of 1.37 when $\mathrm{Ga}_{2} \mathrm{O}_{3}$ was doped at $0.40 \mathrm{~mol} \%$. 


\section{Please insert Figure 6 here}

Through the $C-V$ curves, the parameters related to the Schottky barrier including donor density $\left(N_{d}\right)$, barrier height $\left(\varphi_{b}\right)$, and interface state density $\left(N_{s}\right)$ were calculated, and results were also shown in Table 2 .

It can be seen clearly that with increased $\mathrm{Ga}_{2} \mathrm{O}_{3}$ content, the value of donor density $N_{d}$ monotonously increased, and Ga0.80-1100-2h had the highest value of $2.42 \times 10^{23} \mathrm{~m}^{-3}$, being due to the highest absolute content of $\mathrm{Ga}^{3+}$ formed substitutional solid solution, as listed in Figure 4; According to Fu's opinion, the Schottky barrier height $\left(\varphi_{b}\right)$ formation was attributed to the defect structures at the grain boundary, where the intrinsic acceptor defects were located at the interface and the donor defects were located at the depletion layer ${ }^{[1]}$. In this paper, $\mathrm{Ga}^{3+}$ existed in substitutional solid solution worked as donor and existed in interstitial solid solution worked as acceptor, the former provided an electron to the conduction band and the latter generated a vacancy in the valence band, the higher amount of the difference between these two states, the higher the value of $\varphi_{b}{ }^{[18,40]}$. As shown in Figure 4 , when content of $\mathrm{Ga}^{3+}$ equaled to $0.40 \mathrm{~mol} \%$, specimen had the highest value of $2.24 \mathrm{eV}$. Calculated from Eq. (4), value of $N_{s}$ reached maximum $\left(2.38 \times 10^{16} \mathrm{~m}^{-3}\right)$ when content of $\mathrm{Ga}^{3+}$ equaled to $0.40 \mathrm{~mol} \%$.

Thus, the lower barrier height of samples indicated that although the lower content of IBs (with $\mathrm{Ga}_{2} \mathrm{O}_{3}$ existing in the grain boundary) and sintering process offered sufficient energy to maintain grain-boundary-diffusion activity while suppressing grain-boundary migration, the energy from these factors were insufficient to form a large barrier height. Increased content of IBs benefited grain growth and also led to increased barrier height at single grain boundary. In particular, with increased $\mathrm{Ga}_{2} \mathrm{O}_{3}$ content from $0.20 \mathrm{~mol} \%$ to $0.40 \mathrm{~mol} \%$, the value of $\Phi_{b}$ increased from $1.24 \mathrm{eV}$ to $2.25 \mathrm{eV}$. Another factor worth considering was the influence of bulk density on the electrical properties of $\mathrm{ZnO}$ varistors ${ }^{[41]}$. These two factors determined that the highest value of $E_{\operatorname{lm} A}$ was reached when the content of $\mathrm{Ga}_{2} \mathrm{O}_{3}$ was $0.40 \mathrm{~mol} \%$.

\section{Please insert Table 2 here}

\subsection{Influence of $\mathrm{Ga}_{2} \mathrm{O}_{3}$ content on the mechanical and thermal properties of $\mathrm{ZnO}$ based varistors}

The experimental flexural stress-strain curves and thermal expansion curves of $\mathrm{ZnO}$ varistors are shown in Figures $7 \mathrm{a}$ and $7 \mathrm{~b}$, respectively. Fig. 7 -a reveals that all curves displayed approximately linear behavior, regardless 
of $\mathrm{Ga}_{2} \mathrm{O}_{3}$ content, indicating brittle fracture ${ }^{[42]}$. As shown in Table 3, with increased $\mathrm{Ga}_{2} \mathrm{O}_{3}$ content, $\sigma_{f}, E_{f}$ and $K_{I C}$ initially increased and then decreased, and all reached their maximum values when the content of $\mathrm{Ga}_{2} \mathrm{O}_{3}$ was 0.4 mol\%, these values indicated improvements of $25.29 \%, 47.67 \%$, and $38.51 \%$ compared with those of $\mathrm{ZnO}$ varistors without $\mathrm{Ga}_{2} \mathrm{O}_{3}$, respectively. Moreover, the improvements were $44.54 \%, 90.72 \%$, and $61.41 \%$ compared with the results of Yoshimura ${ }^{[43]}$ due to the toughness of the small grain size and plate-like shape ${ }^{[44,45]}$.

Regarding the CTE, it increased with increased measured temperature, similar to Ni's report ${ }^{[46]}$. At a fixed temperature, with increased $\mathrm{Ga}_{2} \mathrm{O}_{3}$ content, CTE values initially increased and then decreased, and all reached the maximum value when $\mathrm{Ga}_{2} \mathrm{O}_{3}$ content was $0.40 \mathrm{~mol} \%$. The $\mathrm{CTE}$ of $\mathrm{ZnO}$ is reportedly anisotropic, i.e., $6.0 \times 10^{-6}{ }^{\circ} \mathrm{C}$ ${ }^{-1}$ perpendicular to the $c$ axis and $5.0 \times 10^{-6}{ }^{\circ} \mathrm{C}^{-1}$ parallel to the $\mathrm{c}$-axis ${ }^{[40]}$. Plate-like grains formed because the growth of the c-axis was limited in the (0001) face of $\mathrm{ZnO}$ crystal ${ }^{[29]}$, which helped to improve the CTE of the $\mathrm{ZnO}$ varistors. The bulk density of $\mathrm{ZnO}$ varistors also positively influenced the CTE of the materials ${ }^{[40]}$. These two factors worked together to result in an initial increase followed by a decrease in CTE with increased $\mathrm{Ga}_{2} \mathrm{O}_{3}$ content, and value of CTE was $6.65 \times 10^{-6} \mathrm{C}^{-1}$ for $\mathrm{Ga} 0.40-1100-2 \mathrm{~h}$ at $800{ }^{\circ} \mathrm{C}$.

\section{Please insert Figure 7 here}

\section{Please insert Table 3 here}

\section{Mechanism of $\mathrm{Ga}_{2} \mathrm{O}_{3}$ addition on electrical and mechanical properties of $\mathrm{ZnO}$ based Varistors}

Figure 8 shows a schematic model of $\mathrm{Ga}_{2} \mathrm{O}_{3}$ addition on Electrical and mechanical properties of $\mathrm{ZnO}$ based varistors. As reported that the doping of $\mathrm{Ga}^{3+}$ ions in $\mathrm{ZnO}$ varistors possessed three functions ${ }^{[18]}$ :

First, $\mathrm{Ga}^{3+}$ ions replaced $\mathrm{Zn}^{2+}$ in $\mathrm{ZnO}$ lattice to form a substitutional solid solution, in this condition, $\mathrm{Ga}^{3+}$ acted as a donor to release an electron to the conduction band of $\mathrm{ZnO}$ crystal, which would reduce the resistance of $\mathrm{ZnO}$ grains (as shown in Fig.8-a), and the defect reaction equation was as follows ${ }^{[4,16]}$ :

$$
\mathrm{Ga}_{2} \mathrm{O}_{3} \stackrel{\mathrm{Zno}}{\longrightarrow} 2 \mathrm{Ga}_{\mathrm{Zn}}^{+}+2 \mathrm{e}^{-}+2 \mathrm{ZnO}+\frac{1}{2} \mathrm{O}_{2}
$$

Second, when $\mathrm{Ga}^{3+}$ filled in the vacancy of $\mathrm{ZnO}$ lattice, it existed a 'position competition' between $\mathrm{Ga}^{3+}$ and $\mathrm{Zn}_{\mathrm{i}}^{2+}$, which could produce a vacancy in valence band of $\mathrm{ZnO}$ crystal and acted as acceptor to improve the resistance of $\mathrm{ZnO}$ grains (Fig. 8-b), the defect reaction equation was as follows ${ }^{[18]}$ : 


$$
\mathrm{Ga}_{2} \mathrm{O}_{3} \stackrel{\mathrm{Zno}}{\longrightarrow} 2 \mathrm{Ga}_{i}^{-}+\mathrm{h}^{+}+\mathrm{O}_{2}+\frac{1}{2} \mathrm{O}_{2}
$$

Third, when $\mathrm{Ga}^{3+}$ accumulated in the grain boundary of $\mathrm{ZnO}$, the negative free charge at the boundary of $\mathrm{ZnO}$ grain was increased, resulted in an increased of the barrier height and a decreased of the leakage current of $\mathrm{ZnO}$ varistors ${ }^{[15,18]}$. In addition, $\mathrm{Ga}_{2} \mathrm{O}_{3}$ gathered at the grain boundary of $\mathrm{ZnO}$ can be used as an $\mathrm{IB}$-forming dopant to affect the growth behavior of $\mathrm{ZnO}$ grain(Fig. 8-c). Therefore, the addition of $\mathrm{Ga}^{3+}$ and its location play important roles on the electrical and mechanical properties of $\mathrm{ZnO}$ varistors, the change of electrical properties is the result of three factors.

\section{Please insert Figure 8 here}

Combined the result shown in Figure 4 and 8, it can be seen that with the increase of $\mathrm{Ga}_{2} \mathrm{O}_{3}$ content, the content of substitutional solid solution increased flatly, resulted in a monotonously increase of the donor density $N_{d}$; When content of $\mathrm{Ga}^{3+}$ was $0.60 \mathrm{~mol} \%$, amount of substitutional solid solution was approximately equaled to that of grain boundary phase, resulted in a maximum leakage current value of $\mathrm{ZnO}$ varisotrs $\left(4.34 \mu \mathrm{A} \cdot \mathrm{cm}^{-2}\right)$; Also, the rapid increase of grain boundary phase content and a decreased Schottky barrier height $\left(\varphi_{b}\right)$ resulted in a clearly development of plate-like $\mathrm{ZnO}$ grains as shown in Figure 5s-c, $\mathrm{d}$ and e, and the plate-like grain could help to improve the mechanical and properties of $\mathrm{ZnO}$ based varisotrs.

\section{Conclusions}

We investigated the mechanism of $\mathrm{Ga}_{2} \mathrm{O}_{3}$ addition on electrical and mechanical properties of $\mathrm{ZnO}$ based varistors with nanoparticles serving as the main raw materials. The following interesting results were obtained:

1 The added $\mathrm{Ga}_{2} \mathrm{O}_{3}$ preferentially occupied the lattice position of $\mathrm{ZnO}$ crystal via the formation of a substitutional solid solution, which worked as donor to provide an electron to the conduction band; it subsequently occupied the void position via the formation of an interstitial solid solution and worked as acceptor to generate a vacancy in the valence band; Residual $\mathrm{Ga}_{2} \mathrm{O}_{3}$ existed in the grain boundary and mainly served as IBs to stimulate the abnormal growth of $\mathrm{ZnO}$ grain;

2 The formation of substitutional and interstitial solid solutions helped improve the electrical properties, when the $\mathrm{Ga}_{2} \mathrm{O}_{3}$ content was $0.40 \mathrm{~mol} \%, E_{1 m A}, \alpha$ and $K$ were $1235.00 \mathrm{~V} \cdot \mathrm{mm}^{-1}, 46.0$ and 1.37 , respectively, being due to the small particle size and the relative content of donor, acceptor and grain boundary; 
3 The increased content of IBs stimulated the abnormal growth of $\mathrm{ZnO}$ grains, the formed plate-like grain helped improve the mechanical and thermal properties, with the values of $\sigma_{f}, E_{f}$, and $K_{I C}$ reaching $147.43 \mathrm{MPa}, 213.61$ $\mathrm{GPa}$, and $2.05 \mathrm{MPa} \cdot \mathrm{m}^{1 / 2}$, indicated improvements of $25.29 \%, 47.67 \%$, and $38.51 \%$ compared with those of $\mathrm{ZnO}$ varistors without $\mathrm{Ga}_{2} \mathrm{O}_{3}$.

4 The anisotropy of the thermal-expansion coefficient of $\mathrm{ZnO}$ and the limited growth along the c-axis of $\mathrm{ZnO}$ crystal (the growth of plate-like grains meant limited growth of (1000) faces in $\mathrm{ZnO}$ ) led to an initial increase in the CET of $\mathrm{ZnO}$ resistor followed by a decrease with increased $\mathrm{Ga}_{2} \mathrm{O}_{3}$ content. The value of CTE was $6.65 \times 10^{-6 \circ} \mathrm{C}^{-1}$ for $\mathrm{Ga} 0.40-1100-2 \mathrm{~h}$ at $800{ }^{\circ} \mathrm{C}$.

\section{Acknowledgements}

This work was supported by the State Grid Corporation of China Science and Technology Program (5216A01700UD).

\section{Conflict of interest}

There is no interest conflict with others.

\section{Reference}

[1] Zhiyao Fu, Junjia He, Jiazheng Lu, Zhen Fang, Bowen Wang. Investigation of dielectric relaxation and degradation behavior of two-step sintered ZnO varistors[J]. Ceramics International,45 (2019) 21900-21909.

[2] Wenbin Cao, Xin Xie, Youqing Wang, Minge Chen, Yinan Qiao, Pan Wang, Yunxia Zhang, Jianke Liu. Effect of Pr6 $\mathrm{O}_{11}$ doping on the microstructure and electrical properties of $\mathrm{ZnO}$ varistors[J]. Ceramics International,45 (2019) 24777-24783.

[3] Roy, Samarpita, Roy, Tapatee Kundu, Das, Debdulal. Grain growth kinetics of $\mathrm{Er}_{2} \mathrm{O}_{3}$ doped $\mathrm{ZnO}_{-} \mathrm{V}_{2} \mathrm{O}_{5}$ based varistor ceramics[J]. Ceramics International,45 (2019) 24835-24850

[4] Hongfeng Zhao, Jun Hu, Shuiming Chen, Qingyun Xie, Jinliang He. High Nonlinearity and High Voltage Gradient ZnO Varistor Ceramics Tailored by Combining $\mathrm{Ga}_{2} \mathrm{O}_{3}, \mathrm{Al}_{2} \mathrm{O}_{3}$, and $\mathrm{Y}_{2} \mathrm{O}_{3}$ Dopants[J].Journal of American Ceramics Society, 99 (3) (2016) $769-772$.

[5] Pengfei Meng, Jun Hu, Hongfeng Zhao, Jinliang He. High voltage gradient and low residual-voltage ZnO varistor ceramics tailored by doping with $\mathrm{In}_{2} \mathrm{O}_{3}$ and $\mathrm{Al}_{2} \mathrm{O}_{3}[\mathrm{~J}]$. Ceramics International,42 (2016) 19446-19449.

[6] Wenfeng Liu , Lei Zhang, Fanyi Kong, Kangning Wu, Shengtao Li, Jianying Li. Enhanced voltage gradient and energy absorption capability in $\mathrm{ZnO}$ varistor ceramics by using nano-sized $\mathrm{ZnO}$ powders[J]. Journal of Alloys and Compounds, 828 (2020) 154252-1-7. [7] Pengfei Meng, Xiaolei Zhao, Xiao Yang, Jinbo Wu, Qingyun Xie, Jimou He, Jun Hu, Jinliang He. Breakdown phenomenon of ZnO varistors caused by non-uniform distribution of internal pores[J]. Journal of the European Ceramic Society, 39 (2019) 4824-4830.

[8] Rodolfo F.K. Gunnewiek, Claudia P.F. Perdomo, Igor C. Cancellieri, André L.F. Cardoso, Ruth H.G.A. Kiminami. Microwave sintering of a nanostructured low-level additive ZnO-based varistor [J]. Ceramics International, 46 (2020) 15044-15053. 
[9] Jie Liang, Xuetong Zhao, Jianjie Sun, Lulu Ren, Ruijin Liao, Lijun Yang, Weiwei Li. Enhanced electrical properties of ZnO varistor ceramics by spark plasma sintering: Role of annealing[J]. Ceramics International, 46 (2020) 15076-15083.

[10] Jinlou Shen, Yujing Zhang, Mingyu Li, Runxi Bao, Meng Shen, Chi Huang, Guangzu Zhang, Yabing Ke, Honglang Li, Shenglin Jiang. Effects of $\mathrm{Fe}$ and $\mathrm{Al}$ co-doping on the leakage current density and clamp voltage ratio of $\mathrm{ZnO}$ varistor[J]. Journal of Alloys and Compounds, 747 (2018) 1018-1026.

[11] Shuaijun Yang, Dachuan Zhu. Effect of co-doping $\mathrm{Y}_{2} \mathrm{O}_{3}-\mathrm{La}_{2} \mathrm{O}_{3}$ on microstructure and electrical properties of ZnO-based varistor ceramics prepared from nanosize ZnO powder[J]. Journal of Materials Science: Materials in Electronics (2018) 29:3104-3109.

[12] Xuanzhong Cheng, Zhenya Lu, Xingyue Liu, Wenbin Yi, Zhiwu Chen, Xin Wang. Improvement of surge current performances of $\mathrm{ZnO}$ varistor ceramics via $\mathrm{C}_{3} \mathrm{~N}_{4}$-doping[J]. Journal of the European Ceramic Society, 40 (2020) 2390-2395.

[13] Xuejun Ruan, Xin Ren, Wenting Zhou, Xi Xu, Xin Wang, Manyu Wang, Ying Yan, Zheng Yao, Wen Shi, Wenqi Yu. Effects of $\mathrm{SiO}_{2} / \mathrm{Cr}_{2} \mathrm{O}_{3}$ ratios on microstructures and electrical properties of high voltage gradient $\mathrm{ZnO}$ varistors[J]. Journal of Materials Science: Materials in Electronics, 30 (2019)12113-12121.

[14] Bing Cui, Jingpeng Niu, Pai Peng, Liyi Shi, Sanming Du, Juan Liu, Dong Xu. Flash sintering preparation and electrical properties of $\mathrm{ZnO}-\mathrm{Bi}_{2} \mathrm{O}_{3}-\mathrm{M}\left(\mathrm{M}=\mathrm{Cr}_{2} \mathrm{O}_{3}, \mathrm{MnO}_{2}\right.$ or $\left.\mathrm{Co}_{2} \mathrm{O}_{3}\right)$ varistor ceramics[J]. Ceramics International, 46 (2020) 14913-14918.

[15] Meng Peng-fei, Hu Jun, Wu Jin-bo, He Jin-liang. Comprehensive Performances of ZnO Varistors Tailored by Multi-elements Doping[J]. High Voltage Engineering, 44(1)(2018) 241-247.

[16] Hongfeng Zhao , Jinliang He, Jun Hu, Shuiming Chen, Qingyun Xie. High nonlinearity and low residual- voltage ZnO varistor ceramics by synchronously doping $\mathrm{Ga}_{2} \mathrm{O}_{3}$ and $\mathrm{Al}_{2} \mathrm{O}_{3}[\mathrm{~J}]$. Materials Letters 164 (2016) 80-83.

[17] Choon-W. Nahm. Effect of gadolinia addition on varistor characteristics of vanadium oxide-doped zinc oxide ceramics[J]. J Mater Sci: Mater Electron, (2013) 24:4839-4846.

[18] Meng Pengfei, Hu Jun, Wu Jinbo, He Jinliang.High Impulse Current Discharge Capability of ZnO Varistors by Doping Gallium Ions. Proceedings of the CSEE, 37 (24)(2017)7377-7383.

[19] M. Vukovic', G. Brankovic', Z. Marinkovic' Stanojevic, D. Poleti b, Z. Brankovic. Ultra-high breakdown field varistors prepared from individually synthesized nanoprecursors[J]. Journal of the European Ceramic Society, 35 (2015) 1807-1814.

[20] Yuwei He , Student Member, Bengang Wei, Zhengcai Fu , Member, Mingqiu Dai, Jian Liu. MOV Failure Modes and Microstructural Characteristics Under Operating Duty Tests With Multiwaveform Multipulse Currents[J]. IEEE Transactions on Power Delivery, 33(5)(2018)2274-2283.

[21] R. Danzer, B. Kaufmann, P. Supancic. Failure of high power varistor ceramic components[J]. Journal of the European Ceramic Society, 40 (2020) 3766-3770. 
[22] Nadine Raidl, Michael Hofsta"tter and Peter Supancic. Piezotronic Effect on Electrical Characteristics of Bulk ZnO Varistors[J]. Advanced Engineering Materials, 19(4)(2017)1600677-1-5.

[23] Pengkang Xie, Jianping Hu. Influence of Sintering Temperature and $\mathrm{ZrO}_{2}$ Dopants on the Microstructure and Electrical Properties of Zinc Oxide Varistors[J]. IEEE, 7 (2019) 140126-140333.

[24] K. Sandhya, N.S. Chitra PRiya, Deepthi N. Rajendran, Praveen Thappily. Structural and Electrical Properties of Cerium Oxides Doped by $\mathrm{Sb}^{3+}$ and $\mathrm{Bi}^{3+}$ Cations[J]. Journal of Electronic Materials, s11664- 020- 08220-9.

[25] Qianlong Dai, Ruzhong Zuo, Yudong Xu, Liangguo He. A novel temperature-stable $\mathrm{Ba}_{2-\mathrm{x}} \mathrm{Ca}_{\mathrm{x}} \mathrm{MgTi}_{5} \mathrm{O}_{13}$ microwave dielectric ceramic[J]. Journal of the European Ceramic Society, 40 (2020) 376-380.

[26] Peng-zhao Gao, Mo-yu Xu, Zheng Yuan, Lei Cheng, Jian-jun Liang, Han-ning Xiao, Rui-he Chen. Temperature dependence of the mechanical and thermal expansion behaviors of $\mathrm{MoSi}_{2}-\mathrm{RSiC}$ composites with a three-dimensionally (3D) interpenetrated network structure[J]. Journal of Alloys and Compounds, 731 (2018) 1103-1111.

[27] Wang Xinchao, Zhou Bingqing, Yao Ruoqing, Chen Kaiwei, Zhang Haiwen, Zhang Hong. Electrical conductivity and NTC thermal sensitive characteristics of Ga-doped ZnO ceramics[J]. Materials Science and Engineering of Powder Metallurgy, 22(3)(2017) 378-383.

[28] Xiao-Qiang Song, Wen-Zhong Lu, Yi-Hui Lou, Tao Chen, Shi-Wo Ta, Zhen-Xiao Fu, Wen Lei. Synthesis, lattice energy and microwave dielectric properties of $\mathrm{BaCu}_{2-\mathrm{x}} \mathrm{CoxSi}_{2} \mathrm{O}_{7}$ ceramics[J]. Journal of the European Ceramic Society 40 (2020) 3035-3041

[29] Qiu Yu, Wang Li-ming, Xu Li-hui, Shen Yong, Wang Li-ying, Liu Ya-dong Preparation Al-Y co-doped ZnO nanosheets and its photocatalytic degradation performance [J]. Functional Materials, 12(50) (2019) 12097-12102, 12107.

[30] Peng-zhao Gao, Zhi-bo Huang, Hang-bo Zheng, Xiao-pan Liu, Jin Wen, Evgeny V. Rebrov.Temperature dependence of the magnetic properties of monodispersed $\mathrm{Co}_{0.5} \mathrm{Zn}_{0.5} \mathrm{Fe}_{2} \mathrm{O}_{4}$ microtubes derived from different templates[J]. Journal of Materials Science: Materials in Electronics (2019) 30:2809-2820.

[31] Shouli Bai, Xi Sun, Ning Han, Xin Shu, Junli Pan, Haipeng Guo, Shuanghe Liu, Yongjun Feng, Ruixian Luo, Dianqing Li, Aifan Chen. rGO modified nanoplate-assembled $\mathrm{ZnO} / \mathrm{CdO}$ junction for detection of $\mathrm{NO}_{2}[\mathrm{~J}]$. Journal of Hazardous Materials, 394 (2020) 121832-1-9.

[32] Guihua Ren, Xuanyu Ren, Wentao Ju, Yinshan Jiang, Minglei Han. Zhiqiang Dong, Xiaodong Yang, Kuizhou Dou, Bing Xue, Fangfei Li. Controlled vertical growing of $\mathrm{Bi}_{2} \mathrm{O}_{3}$ nano sheets on diatomite disks and its high visible-light photocatalytic performance[J]. Journal of Photochemistry \& Photobiology A: Chemistry, 392 (2020) 112367-1-11.

[33] K. Gurunathan. Photocatalytic hydrogen production using transition metal ions-doped $\gamma-\mathrm{Bi}_{2} \mathrm{O}_{3}$ semiconductor particles[J]. International Journal of Hydrogen Energy, 29 (2004) 933-940. 
[34] Pralay Paul, A.K. Rajarajan, A.K. Debnath, Rekha Rao, T.V. Chandrasekhar Rao. Valence fluctuation and magnetic frustration in Ga substituted $\mathrm{YMnO}_{3}[\mathrm{~J}]$. Journal of Magnetism and Magnetic Materials, 503 (2020) 166617-1-6.

[35] Shravan K. Appani, Ashok Kumar Yadav, D.S. Sutarc, S.N. Jha, D. Bhattacharyya, S.S. Major. X-ray absorption spectroscopy study of Ga-doping in reactively sputtered ZnO films[J]. Thin Solid Films, 701 (2020) 137966-1-9.

[36] Nina Daneu, Aleksander ReWnik, Slavko Bernik. Grain-Growth Phenomena in ZnO Ceramics in the Presence of Inversion Boundaries[J]. Journal of American Ceramics Society, 94(5) (2011) 1619-1626.

[37] K. Hembram, T.N. Rao, R.S. Srinivasa, A.R. Kulkarni. High performance varistors prepared from doped ZnO nanopowders made by pilot-scale flame spray pyrolyzer: Sintering, microstructure and properties[J]. Journal of the European Ceramic Society, 35 (2015) $3535-3544$.

[38] Danyang Liu, Li Yang, Zanyu Chen, Guoqiang Zou, Hongshuai Hou, Jiugang Hu, Xiaobo Ji. Ultra-stable Sb confined into N-doped carbon fibers anodes for high-performance potassium-ion batteries[J]. Science Bulletin, 65 (2020) 1003-1012.

[39] Keyan Li, Dongfeng Xue. Estimation of Electronegativity Values of Elements in Different Valence States [J]. Jorunal of Physical Chemistry A 2006, 110, 11332-11337.

[40] Hua Fu, Guang-lei Zhang . Material Properties of Materals[M]. Peking University Press, 2010.09.

[41] Y. Al-Hadeethi, M.I. Sayyed, Y.S. Rammah. Investigations of the physical, structural, optical and gamma-rays shielding features of $\mathrm{B}_{2} \mathrm{O}_{3}-\mathrm{Bi}_{2} \mathrm{O}_{3}-\mathrm{ZnO}-\mathrm{CaO}$ glasses[J]. Ceramics International, 45 (2019) 20724-20732。

[42] Peng-zhao Gao, Lei Cheng, Zheng Yuan, Xiao-pan Liu, Han-ning Xiao. High temperature mechanical retention characteristics and oxidation behaviors of the $\mathrm{MoSi}_{2}\left(\mathrm{Cr}_{5} \mathrm{Si}_{3}\right)-\mathrm{RSiC}$ composites prepared via a PIP-AAMI combined process[J]. Journal of Advanced Ceramics, 2019, 8(2): 196-208.

[43] H.N. Yoshimura, A.L. Molisani1, N.E. Narita1, J.L.A. Manholetti1, J.M. Cavenaghi. Mechanical Properties and Microstructure of Zinc Oxide Varistor Ceramics[J]. Materials Science Forum, 530-531 (2006)408-413.

[44] Yu Zhu, Dujun Luo, Zongjia Li, Yangwei Wang, Huanwu Cheng, Fuchi Wang, Tao Chen. Effect of sintering temperature on the mechanical properties and microstructures of pressureless -sintered $\mathrm{B}_{4} \mathrm{C} / \mathrm{SiC}$ ceramic composite with carbon additive[J]. Journal of Alloys and Compounds, 820 (2020) 153153-1-10.

[45] Taha, Mohammed A.; Zawrah, Mahmoud F. Fabrication of $\mathrm{Al}_{2} \mathrm{O}_{3}-\mathrm{ZrO}_{2}-\mathrm{Ni}$ composites with improved toughness using nano powders prepared by mechanical alloying [J]. Ceramics International 46 (2020) 19519- 19529.

[46] Yu-feng Ni. First principle calculation of physical properties of $\mathrm{ZnO}$ at high temperature and high pressure[D]. Sichuan Normal University, Master's thesis, 2011.02 


\section{Table Captions}

Table 1 Binding energy (BE) and relative ratio (R.R.) of $\mathrm{Zn}_{2 \mathrm{p}}, \mathrm{Bi}_{4 \mathrm{f}}$ and $\mathrm{Ga}_{2 \mathrm{p}}$ photoelectron peaks for $\mathrm{ZnO}$ based varistor

Table $2 E-J$ and $C-V$ Characteristic Parameters of $\mathrm{ZnO}$ based varistors with various $\mathrm{Ga}_{2} \mathrm{O}_{3}$ and sintered at $1100{ }^{\circ} \mathrm{C}$ for $2 \mathrm{~h}$

Table 3 Mechanical and thermal properties of $\mathrm{ZnO}$ based varistors with different content of $\mathrm{Ga}_{2} \mathrm{O}_{3}$ 


\section{Figure Captions}

Figure $1 \rho$ values of $\mathrm{ZnO}$ based varistors with different amounts of $\mathrm{Ga}_{2} \mathrm{O}_{3}$ added

(a) sintered at different temperatures for $2 \mathrm{~h}$; (b) sintered at $1100{ }^{\circ} \mathrm{C}$ for different holding times

Figure 2 In-situ XRD patterns of $\mathrm{ZnO}$ based varistors with different amounts of $\mathrm{Ga}_{2} \mathrm{O}_{3}$ added: (a) full and (b) amplified patterns

Figure 3 XPS spectra of $\mathrm{ZnO}$ based varistors with different amounts of $\mathrm{Ga}_{2} \mathrm{O}_{3}$ added

(a) survey scan; (b) deconvolution of $\mathrm{Zn}_{2 p}$ spectra; (c) deconvolution of Bi4f spectra; (d) deconvolution of Ga2p spectra

Figure 4 Absolute amount of $\mathrm{Ga}^{3+}$ for different distribution locations versus the increased $\mathrm{Ga}_{2} \mathrm{O}_{3}$ content in $\mathrm{ZnO}$ based varistors

Figure 5 SEM images of polished and etched fracture surfaces of $\mathrm{ZnO}$ based varistors (a-e) andAverage particle size, maximum and minimum aspect ratios of $\mathrm{ZnO}$ varistors (f)

(a) Ga0.00-1100-2 h; (b) Ga0.20-1100-2 h; (c) Ga0.40-1100-2 h; (d) Ga0.60-1100-2 h; (e) Ga0.80-1100-2 h

Figure 6 (a) $E-J$ and (b) $C-V$ plots of $\mathrm{ZnO}$ based varistors with various $\mathrm{Ga}_{2} \mathrm{O}_{3}$ contents and sintered at $1100{ }^{\circ} \mathrm{C}$ for $2 \mathrm{~h}$

Figure 7 Stress-strain (a) and thermal expansion coefficient (b) curves of $\mathrm{ZnO}$ based varistors with different $\mathrm{Ga}_{2} \mathrm{O}_{3}$ contents

Figure 8 Schematic model of $\mathrm{Ga}_{2} \mathrm{O}_{3}$ addition on electrical and mechanical properties of $\mathrm{ZnO}$ based varistors 
Figures
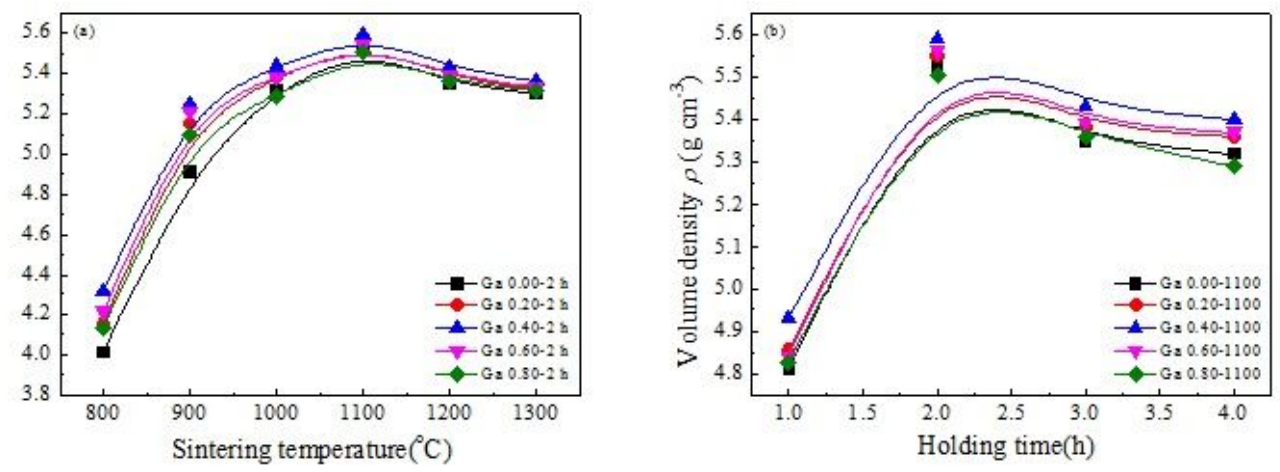

\section{Figure 1}

pvalues of ZnObased varistors with different amounts of Ga203 added (a) sintered at different temperatures for $2 \mathrm{~h}$; (b) sintered at $1100^{\circ} \mathrm{C}$ for different holding times
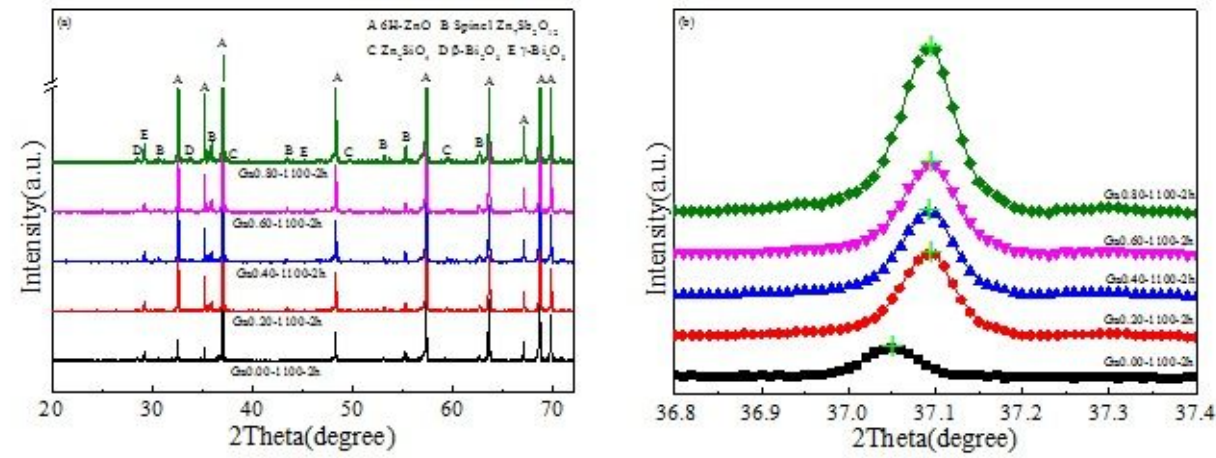

\section{Figure 2}

In-situ XRD patterns of ZnObased varistors with different amounts of Ga203 added: (a) full and (b) amplified patterns 

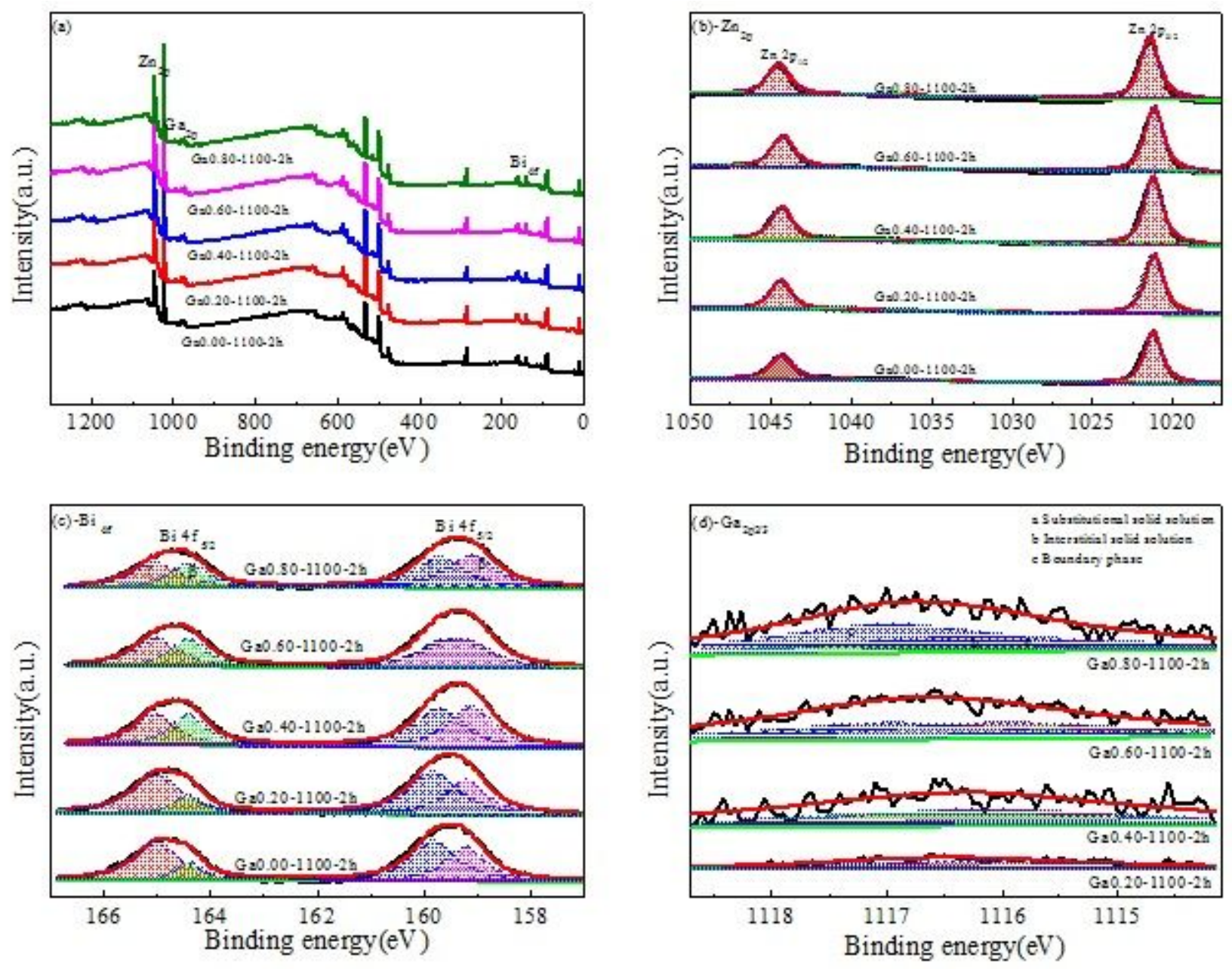

Figure 3

XPS spectra of ZnObased varistors with different amounts of Ga2O3 added (a) survey scan; (b) deconvolution of Zn2p spectra; (c) deconvolution of Bi4f spectra; (d) deconvolution of Ga2p spectra

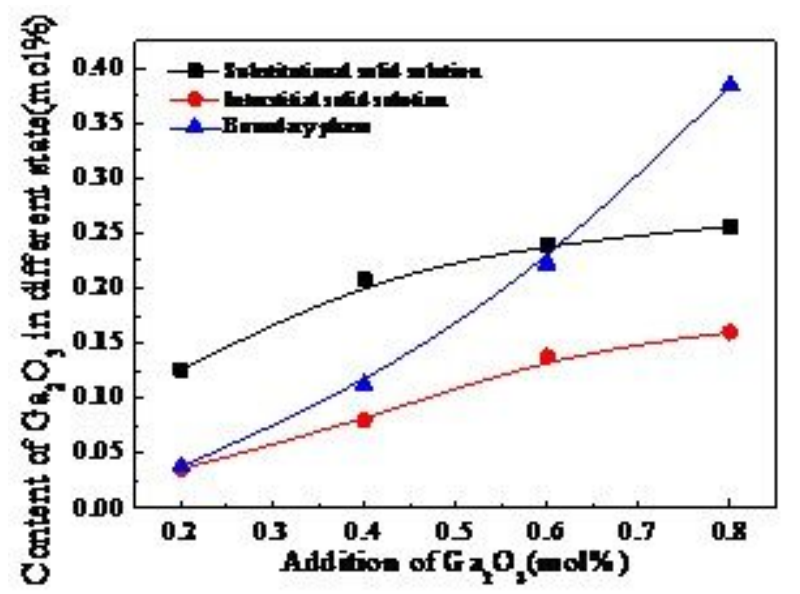

Figure 4 
Absolute amount of Ga3+for different distribution locationsversus the increased Ga2O3contentinZnO based varistors

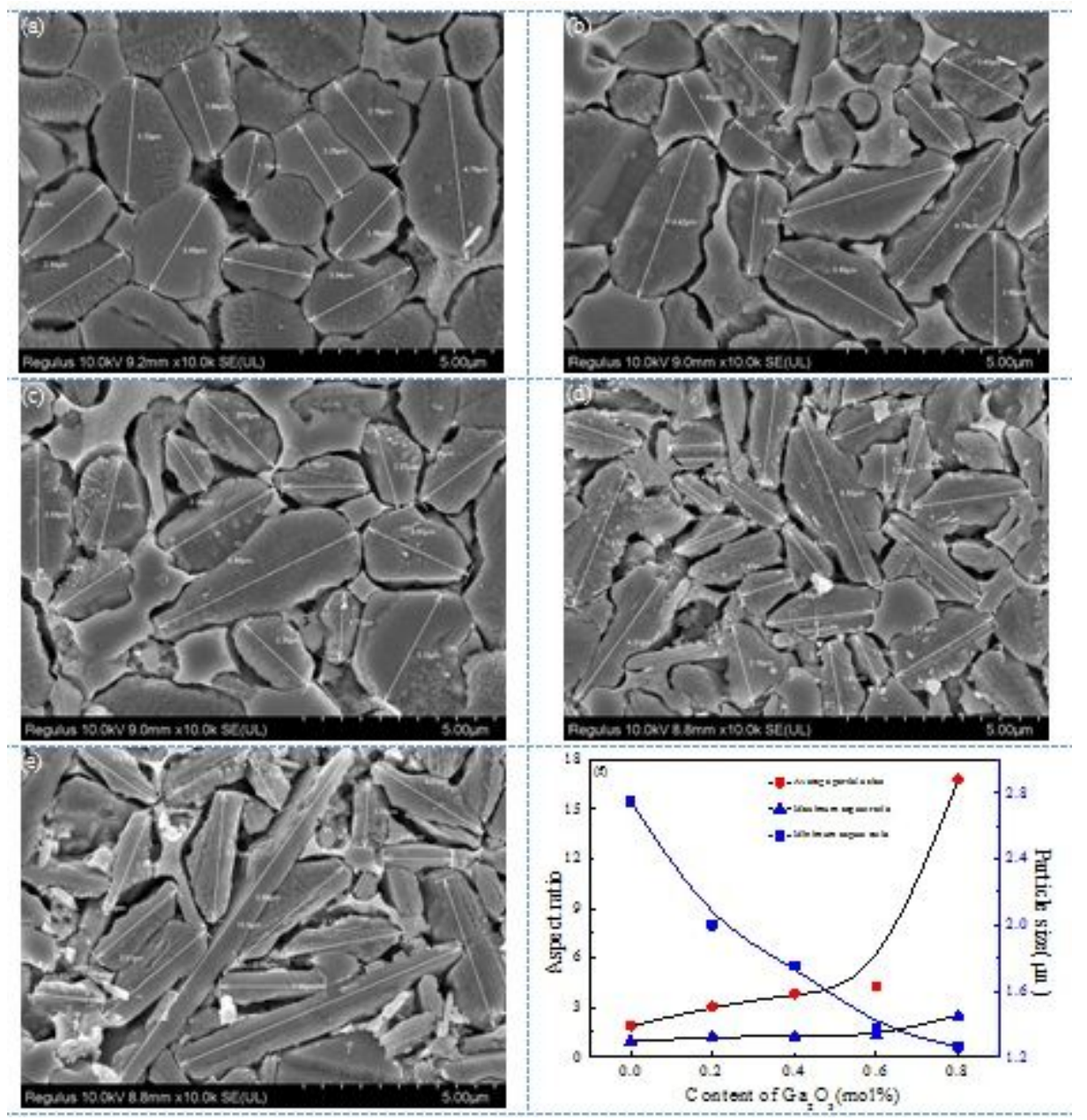

\section{Figure 5}

SEM images of polished and etched fracture surfaces of ZnObased varistors (a-e)andAverage particle size, maximum and minimum aspect ratios of ZnOvaristors(f) (a) Ga0.00-1100-2h; (b) Ga0.20-1100-2h;

(c) Ga0.40-1100-2h; (d) Ga0.60-1100-2h; (e) Ga0.80-1100-2h
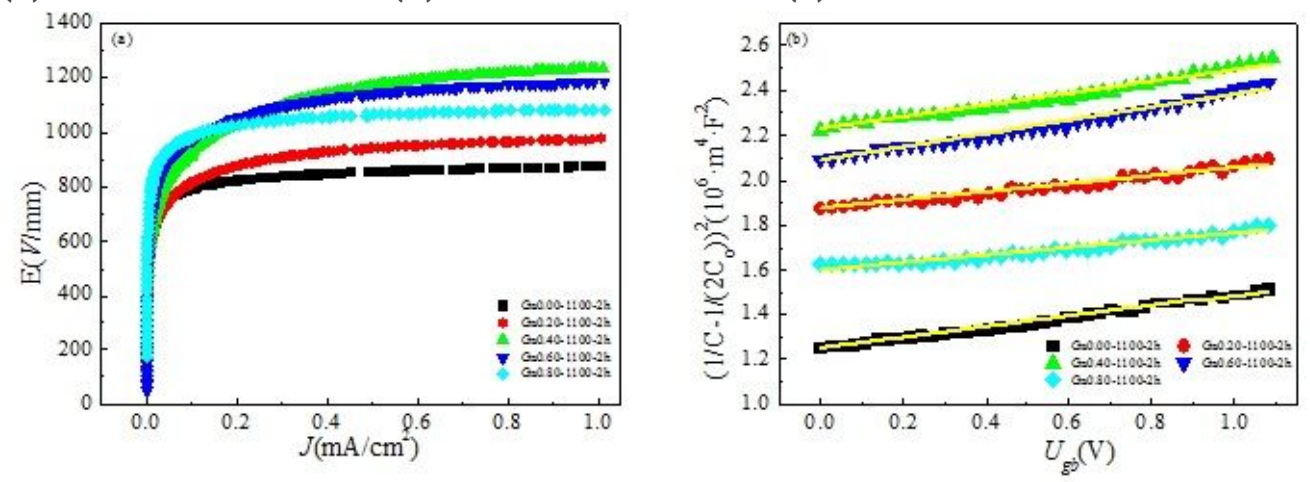

Figure 6 
(a) $\mathrm{E}-\mathrm{J}$ and (b) $\mathrm{C}-\mathrm{V}$ plots of $\mathrm{ZnO}$ based varistors with various $\mathrm{Ga} 2 \mathrm{O} 3$ contents and sintered $1100^{\circ} \mathrm{C}$ for $2 \mathrm{~h}$
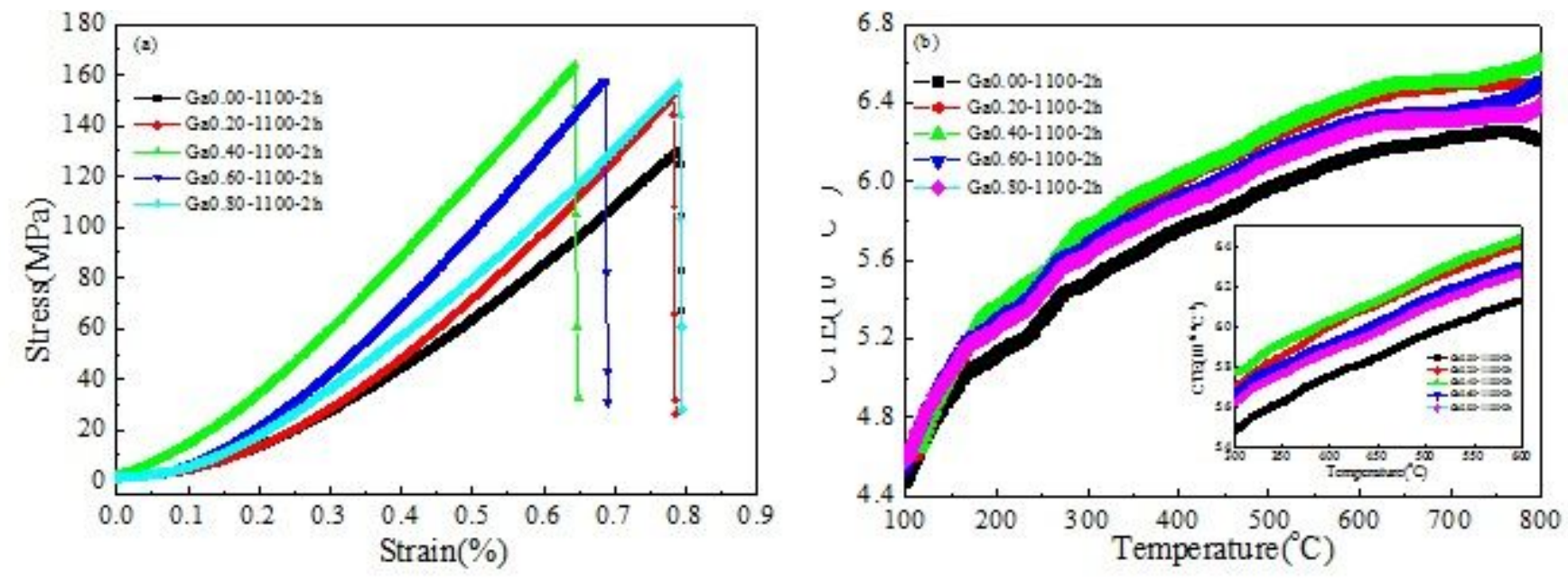

Figure 7

Stress-strain (a) and thermal expansion coefficient (b) curves of $\mathrm{ZnO}$ based varistors with different Ga203 contents
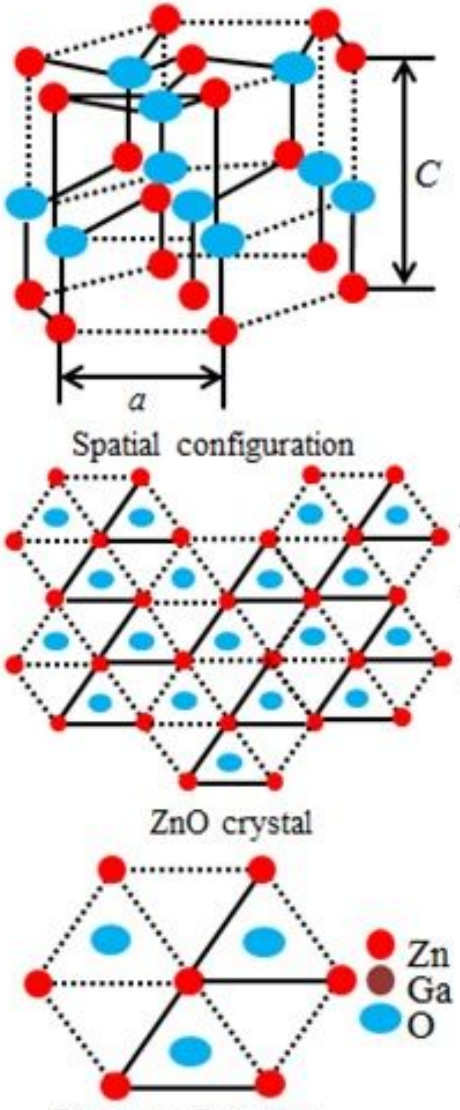

Plane configuration
Substitutional solid solution

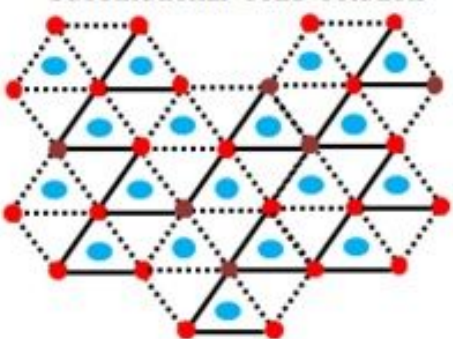

Interstitial solid solution

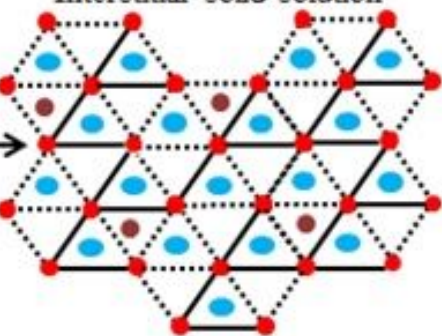

Interstitial solid solution

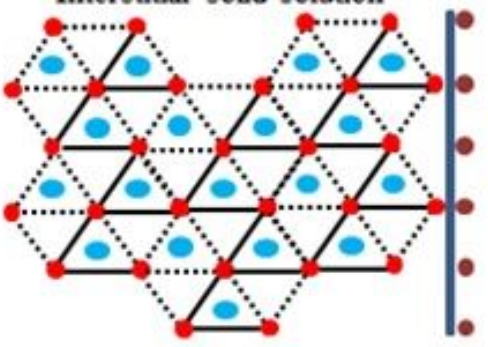

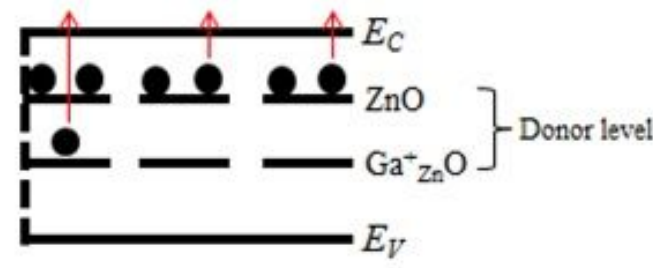

(a)

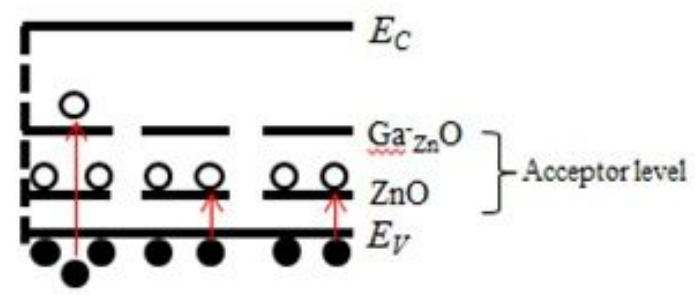

(b)

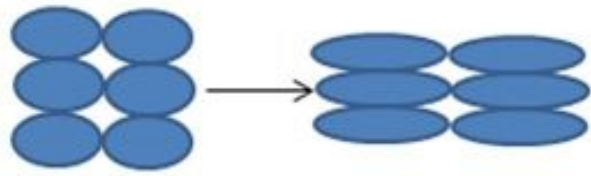

Oval particles

(c) 
Schematic model of Ga2O3 addition on electrical and mechanical properties of $\mathrm{ZnO}$ based varistors

\section{Supplementary Files}

This is a list of supplementary files associated with this preprint. Click to download.

- Tables.pdf

- Tables.pdf 